\section{Randomized Algorithms}

Rajeev Motwani and

Prabhakar Raghavan

"This book will surely exert a powerful influence on the way algorithm design is practiced and taught."-Richard M. Karp 1995490 pp. 47465-5

Hardback $\$ 39.95$

\section{Real-Time}

\section{Computer Vision}

Edited by Christopher M. Brown and Demetri Terzopoulos

The first book devored to this rapidly developing and highly interdisciplinary field of compurer science and engineering. Publications of the Newton Institute 4

1995248 pp. 47278-4 Hardback \$49.95

\section{Movement Control}

Paul Cordo and Stevan Harnad, Editors

"...the choice of topics is interesting and attractive; and the commentaries provide a multifaceted perspective." -Michael Arbib, Center for Neural Engineering, University of Southern California, Los Angeles

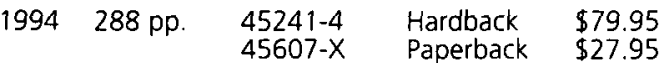

\section{Functional Programming and Input/Ouput \\ Andrew D. Gordon}

Shows how a theory of functional programming can be smoothly extended to admit both an operational semantics for functional $\mathrm{I} / \mathrm{O}$ and verification of programs engaged in $\mathrm{I} / \mathrm{O}$. Distinguished Dissertations in Computer Science 8
$1995 \quad 170 \mathrm{pp}$. 47103-6 Hardback $\$ 39.95$

\section{The MUSE Method for Usability Engineering}

Kee Yong Lim and John Long

Reviews the motivation for developing MUSE, and provides readers with a manual for applying the method.

Cambridge Series in Human-Computer Interaction 8

1995349 pp. 47494-9 Hardback $\$ 49.95$

\section{Computational Geometry in C Joseph O'Rourke}

"...very clearly written and manages to make traditionally difficult-to-explain topics such as point-line duality very understandable..."-Scor Drysdale, SIGACT News

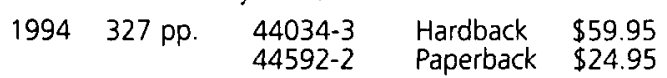

\section{The Uncertain Reasoner's Companion}

A Mathematical Perspective

J.B. Paris

Presents the key results on the subject, concentrating on giving clear mathematical formulations, analyses, justifications, and consequences of the main theories.

Cambridge Tracts in Theoretical Computer Science 39 1995222 pp. 46089-1 Hardback \$39.95

\section{Affine Analysis of Image Sequences \\ Larry S. Shapiro \\ Presents a new computer vision framework for interpreting time-varying imagery.}

Distinguished Dissertations in Computer Science 10

1995 c.200 pp. 55063-7 Hardback \$49.95

\section{The Foundations of Parallel Computing}

David Skillicorn

Provides an accessible account of the latest techniques used to design architecture independent parallel software.

Cambridge International Series on Parallel Computation 7

1995209 pp. 45511-1 Hardback \$39.95

\section{Introduction to Distributed Algorithms}

Gerard Tel

Clear yet rigorous introduction to a large collection of methods and related theory largely developed over the last 15 years. Cambridge International Series on Parallel Computation 6 1995544 pp. 47069-2 Hardback \$49.95

\section{Information Systems Engineering A Formal Approach}

Kees $M$. van Hee

"...an excellent resource."-Choice

$1994 \quad 434$ pp. 45514-6 Hardback \$44.95

Now in paperback...

\section{Logic and Information} Keith Devlin

"Mathematically oriented readers interested in artificial intelligence and human cognition should be able to get new ideas from this well-written book." -P. Jouvelot, Computing Reviews

1991320 pp. $\quad \begin{array}{lll}41030-4 & \text { Hardback } & \$ 39.95 \\ 49971-2 & \text { Paperback } & \$ 19.95\end{array}$ 


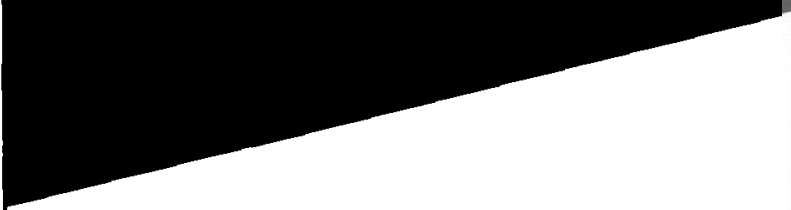 \\ Neural Networks and Qualitative Physics \\ A Viability Approach \\ Jean-Pierre Aubin \\ Makes use of control and viability theory in neural networks and cognitive systems, and set-valued analysis playing a natural and crucial role in qualitative analysis and simulation.}

GXPLORE COMPUTER SCIENCE WTH CAMBRIDGE BOOKS

1995304 pp. 44532-9 Hardback \$49.95

\section{Real-Time Computer Vision Edited by Christopher M. Brown and Demetri Terzopoulos}

The first book devoted to this rapidly developing and highly interdisciplinary field of computer science and engineering.

Publications of the Newton Institute 3

1995 c.256 pp. 47278-4 Hardback \$49.95

\section{Movement Control}

Edited by Paul Cordo and Stevan Harnad

"...the choice of topics is interesting and attractive; and the commentaries provide a multifaceted perspective."

- Michael Arbib, Center for Neural Engineering,

University of Southern California, Los Angeles

1994288 pp. 45241-4 Hardback $\$ 79.95$

$$
\text { 45607-X Paperback } \$ 27.95
$$

\section{Extra Ordinary Human-Computer Interaction}

Interfaces for Users with Disabilities

\section{Edited by Alistair D.N. Edwards}

The current status of the development of disability interfaces, identifying major obstacles to further progress in this field and articulating ways to accelerate progress.

Cambridge Series in Human-Computer Interaction 7

1995 c.287 pp. $43413-0$ Hardback $\$ 49.95$

\section{Parallel Computing}

Principles and Practice

\section{T.J. Fountain}

The principles of parallel computing, with explanations of why, where, and how parallel computing is used.

1995360 pp. $45131-0$ Hardback $\$ 39.95$

\section{Abductive Inference}

Computation, Philosophy, Technology

Edited by John R. Josephson

New ideas about inferential and information-processing foundations for knowledge and certainty.

1994320 pp. $43461-0$ Hardback $\$ 49.95$
Engineering Design

A Synthesis of Views

Clive L. Dym

Clarifies the issues in engineering

design, providing an operational

definition of engineering design

and an explication of design as

a discipline.

$1994223 \mathrm{pp}$

44224-9 Hardback \$49.95

47760-3 Paperback $\$ 19.95$

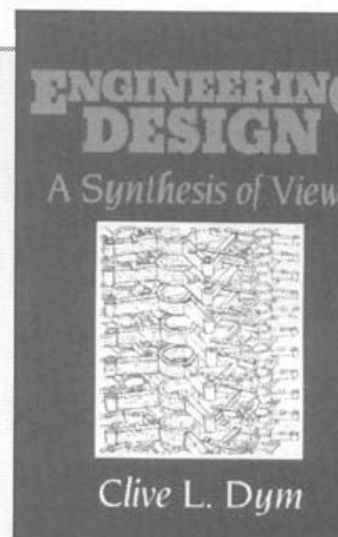

\section{The Uncertain Reasoner's Companion}

A Mathematical Perspective

\section{J.B. Paris}

The key results on the subject, concentrating on giving clear mathematical formulations, analyses, justifications, and consequences of the main theories about uncertain reasoning. Cambridge Tracts in Theoretical Computer Science 39 1995222 pp. 46089-1 Hardback \$39.95

\section{The Logical Status of Diagrams Sun-Joo Shin}

Challenges the prejudice against visualization in the history of logic and mathematics by providing a formal foundation for work on natural reasoning in a visual mode.

1995208 pp. 46157-X Hardback $\$ 39.95$

\section{Introduction to Distributed Algorithms Gerard Tel}

Clear yet rigorous introduction to a large collection of methods and theory largely developed over the last 15 years. Cambridge International Series on Parallel Computation 6 1995544 pp. 47069-2 Hardback \$49.95

\section{Handshake Circuits}

An Asynchronous Architecture for VLSI Programming Kees van Berkel

Describes a programming approach to the design of digital VLSI circuits.

Cambridge International Series on Parallel Computation 5 1994240 pp. 45254-6 Hardback \$39.95

\section{Information Systems Engineering}

A Formal Approach

Kees M. van Hee

Concentrates on discrete dynamic systems and information and logistical systems, and develops an integrated formalism that can be used as a prototyping language.

1994434 pp. 45514-6 Hardback \$44.95 


\section{A \\ Engineering Design, \\ Analysis and Manufacturing}

\section{INSTRUCTIONS FOR AUTHORS}

\section{AIMS AND SCOPE}

AI EDAM: Artificial Intelligence for Engineering Design, Anatysis and Manufacturing is an archival research journal that is intended to reach two audiences: engineers and designers who see AI technologies as powerful means for solving difficult engineering problems; and researchers in AI and computer science who are interested in applications of $\mathrm{AI}$ and in the theoretical issues that arise from such applications. The Editor is specifically seeking original articles that develop new and interesting applications based on the most up-to-date research in all branches and phases of engineering, including analysis, synthesis and design; manufacturing and assembly; and concurrent engineering. The journal is interested in the use of AI in planning, design, analysis, simulation, spatial reasoning and graphics, manufacturing, assembly, process planning, scheduling, numerical analysis, and optimization. Areas of special interest include: knowledge-based (expert) systems for engineering, including knowledge acquisition and representation, control, and system architectures; theoretical work on the modeling of engineering problem-solving and design processes; the integration of AI-based techniques with numerical analysis tools, graphics and solid modeling packages, and engineering databases; and engineering applications of knowledge-based vision and of natural language processing.

\section{ORIGINALITY AND COPYRIGHT}

To be considered for publication in $A I E D A M$ a manuscript cannot have been published previously, nor can it be under review for publication elsewhere. Papers with multiple authors are reviewed with the assumption that all authors have approved the submitted manuscript and concur in its submission to AIEDAM. A Transfer of Copyright Agreement must be executed before an article can be published. Government authors whose articles were created in the course of their employment must so certify in lieu of copyright transfer. Authors are responsible for obtaining written permission from the copyright owners to reprint any previously published material included in their article.

\section{MANUSCRIPT SUBMISSION AND REVIEW}

Three high quality copies of articles, in English, should be submitted to the Editor.

Professor Clive L. Dym, Editor

AI EDAM

Department of Engineering

Harvey Mudd College

Claremont, CA 91711

Phone: (909) 621-8853

Fax: (909) 621-8967

E-mail: Clive_Dym @hmc.edu

Books for review should be submitted to the section editor.

Professor David C. Brown, Book Review Editor

AI EDAM

Department of Computer Science

Fuller Labs 131

100 Institute Road

Worcester Polytechnic Institute

Worcester, MA 01609

Phone: (508) 831-5618

Fax: (508) 831-5776

E-mail: deb@owl.wpi.edu

Photocopies of typescripts will not be accepted for publication. For refereeing purposes only, good photocopies may be submitted. Upon acceptance of the manuscript the top copy and the original illustrations should be submitted for publication. Authors of accepted manuscripts are urged to submit cheir final manuscripts on diskette as well as on hard copy, identifying what software was used.

\section{MANUSCRIPT PREPARATION AND STYLE}

Paper should be typed in double spacing throughout, including tables, footnotes, references and legends to tables and fig- ures. One side of the paper, only, should be used and there should be a margin of at least $2.5 \mathrm{~cm}$ all around. The position of tables and figures should be clearly indicated, in sequence, in the text. Tables, footnotes and legends to figures should be typed separately. Where it is essential for clear crossreferencing, particularly in mathematically-orientated material, paragraphs and subparagraphs may be numbered, and the decimal system should be used, i.e. 1.1.1., 1.1.2., etc. A short running title of not more than 40 characters (including spaces) should be indicated if the full title is longer than this. The name of the laboratory where the work has been carried out should be indicated on the title page and the full postal address for the despatch of proofs and offprints should be included on a separate page. Minor corrections to the manuscript may be typed or neatly printed in ink; retyping is required for significant changes. Numbers should be spelled out when they occur at the beginning of a sentence; use Arabic numerals elsewhere.

\section{MANUSCRIPT ELEMENTS AND ORDER}

Unless there are obvious and compelling reasons for variation (e.g. review articles, short communications), manuscripts should be organized as follows:

Title page. This is page 1 . The title should be concise, informative, and free of abbreviations, chemical formulae, technical jargon, and esoteric terms. This page should include (a) the article's full title, (b) names and affiliations of all authors, (c) the name, mailing address, and telephone number of the corresponding author, (d) the address for reprint requests if different from that of the corresponding author, (e) a short title of 50 characters or less, and (f) a list of the number of manuscript pages, number of tables, and number of figures.

Abstract and keywords page. This is page 2 and should include (a) the article's full title, (b) an abstract of no more than 300 words, and (c) up to 5 keywords or phrases that reflect the content and major thrust of the article. The abstract should give a succinct account of the objective, methods, results, and significance of the subject matter.

Introduction. This section begins on page 3 and should clearly state the objective of the research in the context of previous work bearing directly on the subject. An extensive review of the literature is not usually appropriate.

Citations in text. Customary abbreviations will be accepted and the authors are recommended to employ Système Internationale (SI/metric) units. Special and unusual symbols should be clearly identified, especially if handwritten. Spel out acronyms at first use, but use only acronyms thereafter. All equipment supplies and products stated in the article should have the manufacturer name and location identified at first mention.

Tables. Tables should be numbered consecutively with Arabic numerals and each should be typed double-spaced on a separate sheet. All tables are to be grouped together after the references. A short explanatory title and column headings should make the table intelligible without reference to the text. All tables must be cited and their approximate positions indicated in the text.

Figures and legends. The number of figures should be the minimum necessary to make the essential points of the paper. Figures should be supplied no larger than $8 \times 10^{\text {* }}$ (approx. $200 \times 250 \mathrm{~mm}$ ) and must be camera-ready. Photographs will be accepted only if the information cannot be presented easily in any other form. Explanation and keys should, as far as possible, be placed in the legends. Photographs for halftone reproduction must be on white glossy paper. Figures should be composed to occupy a single column $(8.3 \mathrm{~cm})$ or two columns $(17 \mathrm{~cm})$ after reduction. Diagrams and illustrations must have a professional appearance and be typed or drawn with sharp, black lettering to permit reduction. To assure legibility, letters, numbers, and symbols on figures should have a minimum height of $1 \mathrm{~mm}$ when reduced.

Artwork should normally be in black and white; if authors have color figures, the publisher will provide a price quotation for the additional production costs. All figures must be identified on the back with the short title of the paper, figure number, and figure orientation (top or bottom). Preferably, figures should be mounted on heavy sheets of the same size as the manuscript. Four complete sets of figures should be carefully packaged in protective envelopes, one to accompany each copy of the manuscript. Each figure must be cited and its approximate position clearly indicted within the text.

Figures must be numbered consecutively with Arabic numerals and be accompanied by a descriptive caption typed double-spaced on a separate sheet. The captions, collected at the end of the manuscript, should concisely describe the figure and identify any symbols and/or calibration bars.

References. Entries should be listed alphabetically by lead author at the end of the paper. All authors' names should be in. cluded, followed by the year of publication, the full title of the journal, volume, issue number, and inclusive page num. bers. For books, the full title should be given, followed by the editors, volume number (if any), page numbers, publisher and place of publication. Citations in the text should read: Brown and Smith (1973), but (Brown \& Smith, 1973). Where there are more than two authors the citation should read: Brown et al. (1973). The conventional Brown (1973a), Brown (1973b) should be used where more than one paper by the author(s) has appeared in the same year. Brief examples:

\section{Journal or Magazine article}

Schank, R.C. (1991). Where's the AI? AI Magazine 12(4), 38- 49 .

Segre, M.A. (1991). Learning how to plan. Robotics and Autonomous Syst. 8(I-2), 93-111.

\section{Book}

Dym, C.L. (1994), Engineering design: A synthesis of views. Cambridge University Press, New York.

\section{Chapter in an edited book}

Quinlan, J.R. (1983). Learning efficient classification procedures and their application to chess end games. In $\mathrm{Ma}$ chine Learning: An Artificial Intelligence Approach, (Carbonell, J.G., et al., Eds.), Vol. 1, pp. 463-482. Morgan Kaufmann, Los Altos, California.

\section{Proceedings}

Craw, S., \& Sleeman, D. (1990). Automating the refinement of knowledge based systems. Proc. Ninth Europ. Al Conf., 167-172.

Proceedings with publisher identified

Mittal, S., \& Frayman, F. (1989). Towards a generic model of configuration tasks. Proc. Eleventh Int. Joint Conf: Artificial Intelligence, pp. 1395-1401. Morgan Kaufmann, Los Altos, California.

The alphabetical list of references begins a new page, and must be typed double-spaced. Each in-text citation must have a corresponding reference and vice versa. List works by different authors who are cited within the same parentheses in chronological order, beginning with the earlier work. Journal titles should not be abbreviated. Only published articles and articles in press should appear in this list. Responsibility for the accuracy of references cited lies with the authors.

Author biographies. Brief author biographies will be printed at the end of each paper; they should not exceed 100 words for each author.

\section{COPYEDITING AND PAGE PROOFS}

The publisher reserves the right to copyedit manuscripts to conform to the style of $A I E D A M$. The corresponding author will receive page proofs for final proofreading. No rewriting of the final accepted manuscript is permitted at the proof stage, and substantial changes may be charged to the authors.

\section{OFFPRINTS}

The corresponding author will receive 50 free article offprints. A form will accompany the page proofs allowing orders for complete copies of the issue and for the purchase of additional offprints. Offprint requirements of all coauthors should be included on this form. Orders received after issue printing will be subject to a $50 \%$ reprint surcharge. 


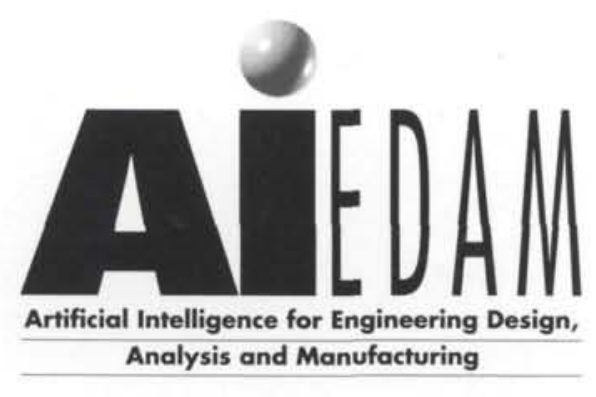

VOLUME 9

SEPTEMBER 1995

NUMBER 4

\section{Special Issue: Conflict Management in Design}

\section{Guest Editorial}

IAN F.C. SMITH

Conflict Management in Design. .

Articles

Vincent OH and John Sharpe

Conflict Management in an Interdisciplinary Design Environment

MARK KLEIN

Conflict Management as Part of an Integrated Exception Handling Approach

Charles J. Petrie, Teresa A. Webster, and Mark R. Cutkosky

Using Pareto Optimality to Coordinate Distributed Agents . .

Daniel R. KuOKKa and Larry T. HaRada

Communication Infrastructure for Concurrent Engineering

B.V. Dunskus, D.L. Grecu, D.C. Brown, and I. Berker

Using Single Function Agents to Investigate Conflict

Djamila Haroud, Sylvie Boulanger, Esther Gelle, and Ian Smith

Management of Conflict for Preliminary Engineering Design Tasks.

Dennis Bahler, Catherine Dupont, and James Bowen

Mixed Quantitative/Qualitative Method for Evaluating Compromise Solutions

to Conflicts in Collaborative Design

Rose Dieng

Conflict Management in Knowledge Acquisition

Frances M.T. Brazier, Pieter H.G. van Langen, and Jan Treur

Modelling Conflict Management in Design: An Explicit Approach. 